\title{
Early Stages of Calciphylaxis: Are Skin Biopsies the Answer?
}

\author{
Joerg Latus ${ }^{\mathrm{a}}$ Martin Kimmel ${ }^{\mathrm{a}} \quad$ German Ott $^{\mathrm{b}} \quad$ Evelyn Ting $^{\mathrm{b}}$ \\ M. Dominik Alscher ${ }^{a}$ Niko Braun ${ }^{a}$

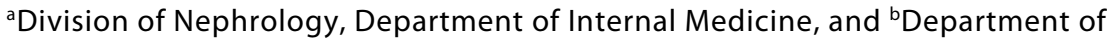 \\ Clinical Pathology, Robert Bosch Hospital, Stuttgart, Germany
}

\section{Key Words}

Calcific uremic arteriolopathy $\cdot$ Calciphylaxis · Deep skin biopsy $\cdot$ Necrosis

\begin{abstract}
Calciphylaxis, nowadays called calcific uremic arteriolopathy (CUA), is a rare but lifethreatening syndrome characterized by systemic medial calcification and arterial occlusion of the arterioles, leading to skin necrosis. Actually, the pathogenesis of CUA is complex and poorly understood. The vast majority of published cases presented with ulcers. We present a 71-year-old male who was referred to the Nephrology Department for evaluation and therapy for refractory edema of both legs. There were no subcutaneous plaques, ulcers or other focal lesions. We performed a deep skin biopsy of the thigh. After the biopsy, the patient developed necrosis around the sampling location. Diagnosing CUA in the early stages of the disease, however, is challenging. Should a skin biopsy be performed in the early stages of CUA in patients without ulcerations, knowing the risk of inducing ulcerations, or should an intensive treatment - after considering clinical manifestations, other noninvasive diagnostic tools (bone scan, X-ray mammography technique) and laboratory tests - be started? Although there are no specific diagnostic laboratory tests for CUA and the clinical manifestations of CUA are similar to those of other disorders, a skin biopsy is not routinely recommended to confirm the diagnosis of early-stage calciphylaxis.
\end{abstract}

\section{Introduction}

Calciphylaxis, nowadays called calcific uremic arteriolopathy (CUA), is a rare but lifethreatening syndrome characterized by systemic medial calcification and arterial occlusion of the arterioles, leading to skin necrosis. CUA characteristically occurs in patients with end-stage renal disease and secondary hyperparathyroidism or those who have recently received a renal transplant; however, it has also been described in patients with normal renal function and calcium/phosphate metabolism [1-3]. There is an 
increasing prevalence of this condition, as high as $4.1 \%$, in patients with end-stage renal disease [4]. The most common cause in nonuremic patients is primary hyperparathyroidism [5]. Actually, the pathogenesis of CUA is complex and poorly understood. The vast majority of published cases presented with ulcers.

\section{Case Report}

A 71-year-old Caucasian male, with a history of hypertension, coronary artery disease, and end-stage renal disease caused by nephrosclerosis, who had been on peritoneal dialysis for the previous 9 months, was referred to the Nephrology Department for evaluation and therapy for refractory edema of both legs. Clinical examination showed erythema, thickening of the skin and symmetric painful swelling extending from both feet up to the groin. There were no subcutaneous plaques, ulcers or other focal lesions (fig. 1a).

An MRI was performed to facilitate biopsy planning and to rule out dermatomyositis, nephrogenic systemic fibrosis and fasciitis. Findings were unspecific concerning edema and signs of fasciitis; no focal enhancement was found. A deep skin biopsy of the thigh was also performed. Biopsy findings are shown in fig. $1 \mathrm{~b}$.

After diagnosing calciphylaxis, the patient was switched to daily hemodialysis. Treatment with vitamin D, calcium-containing phosphorous binders and phenprocoumon was stopped, and a regimen consisting of cinacalcet, vitamin $\mathrm{K}$ and sodium thiosulfate therapy was immediately started.

Two days after the biopsy, the patient developed necrosis around the sampling location. Over the next 2 weeks, the extent of the necrosis increased considerably and reached a maximum extension of $220 \mathrm{~mm}$ (fig. 1c). Daily surgical consultations guaranteed optimal wound care. Despite a complex and multidisciplinary approach, the deep ulcer did not heal and new focal skin lesions came up. It was not until after several months of intense therapy that the disease process was stopped and a slight improvement was noticed.

\section{Discussion}

Clinical presentation of late-stage CUA is unique and a skin biopsy is often not required. The diagnosis of CUA in the early stages of the disease, however, is challenging. For instance, CUA can be mistaken for nephrogenic systemic fibrosis which can manifest as erythematous papules that coalesce into erythematous to brawny plaques, with the skin involved becoming woody and thickened in texture [6]. The importance of obtaining a skin biopsy to differentiate, for example, between these two disorders is essential and knowledge of the exact tissue histology is helpful in confirming a strong clinical suspicion.

Should a skin biopsy be performed in the early stages of CUA in patients without ulcerations, knowing the risk of inducing ulcerations, or should an intensive treatment - after considering clinical manifestations, other noninvasive diagnostic tools (bone scan, X-ray mammography technique) and laboratory tests - be started? This question is not easily answered. Definitive criteria to diagnose CUA are surely needed in order to avoid inconclusive skin biopsies as well as the risk of inducing ulcerations stemming from local tissue trauma following a skin biopsy. Skin biopsy results are helpful in cases of doubt. 
Although there are no specific diagnostic laboratory tests for CUA and the clinical manifestations of CUA are similar to those of other disorders, a skin biopsy is not routinely recommended to confirm the diagnosis of early-stage calciphylaxis.

\section{Disclosure Statement}

The authors report no conflicts of interest. 


\begin{tabular}{r|l|l|l}
$\begin{array}{c}\text { Case Reports in } \\
\text { Dermatology }\end{array}$ & $\begin{array}{l}\text { Case Rep Dermatol 2011;3:201-205 } \\
\text { DOI: } 10.1159 / 000333007\end{array}$ & $\begin{array}{l}\text { Published online: } \\
\text { September 23, 2011 }\end{array}$ & $\begin{array}{l}\text { I 2011 S. Karger AG, Basel } \\
\text { ISSN 1662-6567 } \\
\text { www.karger.com/cde }\end{array}$ \\
\hline
\end{tabular}
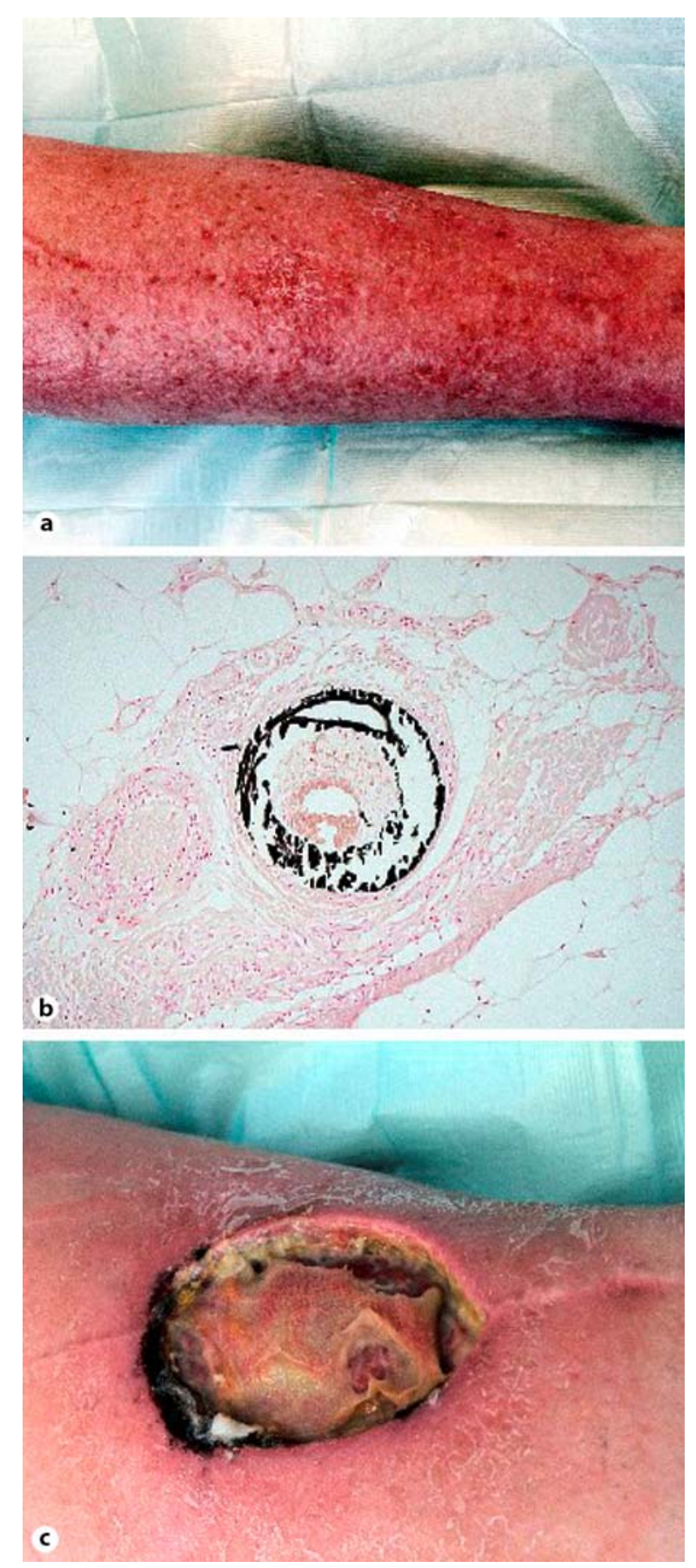

Fig. 1. a The patient's left leg, on admission, with edema and erythema but without subcutaneous plaques, ulcers or other focal lesions. $\mathbf{b}$ Histology of the skin biopsy shows concentric calcification of the media layer of small arteriolar vessels, subintimal fibrosis and, consequently, arterial occlusion (von Kossa stain; $\times 400$ ). There were no signs of underlying vasculitis. c The necrotic area expanded considerably and reached a maximum of $220 \mathrm{~mm}$ two weeks after the skin biopsy. 


\section{References}

1 Janigan DT, Hirsch DJ, Klassen GA, MacDonald AS: Calcified subcutaneous arterioles with infarcts of the subcutis and skin ('calciphylaxis') in chronic renal failure. Am J Kidney Dis 2000;35:588-597.

-2 Perloff LJ, Spence RK, Grossman RA, Barker CF: Lethal post-transplantation calcinosis. Transplantation 1979;27:21-25.

3 Barri YM, Graves GS, Knochel JP: Calciphylaxis in a patient with Crohn's disease in the absence of end-stage renal disease. Am J Kidney Dis 1997;29:773-776.

4 Angelis M, Wong LL, Myers SA, Wong LM: Calciphylaxis in patients on hemodialysis: a prevalence study. Surgery 1997;122:1083-1089, discussion 1089-1090.

-5 Nigwekar SU, Wolf M, Sterns RH, Hix JK: Calciphylaxis from nonuremic causes: a systematic review. Clin J Am Soc Nephrol 2008;3:1139-1143.

6 Cowper SE: Nephrogenic fibrosing dermopathy: the first 6 years. Curr Opin Rheumatol 2003;15:785-790.

Neither the manuscript nor any significant part of it are under consideration for publication elsewhere or have appeared before. 